\title{
KE ARAH PENINGKATAN PRESTASI SEKTOR PERKHIDMATAN PERUSAHAAN KECIL DAN SEDERHANA MELALUI AMALAN PERKHIDMATAN LEAN: KERANGKA KONSEPTUAL
}

\author{
SHAH ISKANDAR FAHMIE RAMLEE* \\ NORHANI BAKRI** \\ NIK HASNAA NIK MAHMOOD***
}

\begin{abstract}
Abstrak
Sistem penyampaian perkhidmatan yang cekap adalah menjadi keutamaan dalam persekitaran ekonomi yang sentiasa berubah. Berdasarkan kepada sorotan literatur, amalan perkhidmatan lean boleh diukur melalui sepuluh elemen - pelan pengenalpastian pembaziran, orientasi tarik, pembangunan dan reka bentuk perkhidmatan baru, kepelbagaian fungsi sumber manusia, penggunaan teknologi maklumat, keseragaman tugas, penglibatan pelanggan, hubungan aktiviti hadapan dan belakang syarikat, kepelbagaian perkhidmatan yang ditawarkan dan susun atur perkhidmatan lean. Namun begitu, dalam sektor perkhidmatan PKS kajian masih kurang dijalankan walaupun pelaksanaannya didapati mampu meningkatkan prestasi. Oleh itu, kertas kerangka konseptual ini memberikan tumpuan kepada amalan perkhidmatan lean yang dilaksanakan oleh syarikat PKS dan hubungannya dengan prestasi.
\end{abstract}

Kata Kunci: Amalan Perkhidmatan Lean, Sektor Perkhidmatan Perusahaan Kecil dan Sederhana, Prestasi.

* Pensyarah, Sumber Manusia di Fakulti Keusahawanan dan Perniagaan, Universiti Malaysia Kelantan

** PhD, Profesor Madya dan Ketua Jabatan Sumber Manusia di Fakulti Pengurusan, Universiti Teknologi Malaysia Skudai

*** PhD, Profesor Madya dan Ketua Jabatan Pembangunan Sumber Manusia di Sekolah Razak, Universiti Teknologi Malaysia Kuala Lumpur 


\begin{abstract}
An efficient service delivery system is a priority in the rapidly changing economics environment. Based on literature review, ten elements have been identified as a driver to the success of lean services implementation - value stream mapping, pull oriented, design and development of new services, multifunctional of human resource, utilisation of information technology, standardization of work, customer involvement, relation between front and back of organization activities, provide a wide range of services and lean services flow. However, studies in this field are still lacking, particularly in the SME's service sector. Therefore, this conceptual framework focuses on lean service practices adopted by SME's and its relationship with performance.
\end{abstract}

Keywords: Lean Service Practices, Service Sector Small and Medium Entreprise and Performance

* Pensyarah, Sumber Manusia di Fakulti Keusahawanan dan Perniagaan, Universiti Malaysia Kelantan

** PhD, Profesor Madya dan Ketua Jabatan Sumber Manusia di Fakulti Pengurusan, Universiti Teknologi Malaysia Skudai

*** PhD, Profesor Madya dan Ketua Jabatan Pembangunan Sumber Manusia di Sekolah Razak, Universiti Teknologi Malaysia Kuala Lumpur

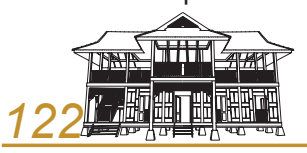

TENIAT 


\subsection{Pengenalan}

Syarikat Perusahaan Kecil dan Sederhana (PKS) pada masa kini beroperasi dalam suasana ekonomi global yang tidak menentu, perubahan pantas teknologi dan kehendak pengguna yang tidak terbatas serta sentiasa berubah (Mohd Rose et. al, 2009; Alsmadi et. al, 2012). Keadaan ini menuntut syarikat untuk memberikan perkhidmatan mereka dengan cekap, pantas serta berkesan untuk mengelakkan pembaziran sumber dan peningkatan kos dalam operasi harian mereka (Dahlgaard dan Dahlgaard-Park, 2006; Erwin et. al, 2016). Kegagalan syarikat memberikan perkhidmatan yang berkualiti menyebabkan pengguna akan hilang kepercayaan dan beralih kepada syarikat yang lain untuk mendapatkan perkhidmatan.

Oleh itu, amalan perkhidmatan lean telah dikenalpasti sebagai salah satu inisiatif penambahbaikan untuk menyingkirkan pembaziran (Womack dan Jones, 1996; Taylor et. al, 2012; Erwin et. al, 2016) dalam aliran, proses dan operasi dalaman sesebuah syarikat. Selain itu, dengan menggunakan prinsip Lean pembaziran seperti kos, masa dan usaha pekerja dapat dielakkan.

Amalan perkhidmatan lean memberikan penekanan kepada prinsip "to do more with less" yang membawa maksud mengurangkan pembaziran dengan mempertingkatkan nilai tambah kepada pelanggan dan prinsip tersebut merupakan pengdaptasian daripada Sistem Pengeluaran Toyota (Toyota Production System (TPS)) (Womack et. al, 2003).

Walaubagaimanapun, kajian berkaitan dengan sektor perkhidmatan Perusahaan Kecil dan Sederhana (PKS) masih kurang sedangkan sektor ini berhadapan dengan pelbagai cabaran untuk terus berkembang dalam pasaran tempatan dan antarabangsa. Cabaran-cabaran tersebut termasuklah kekurangan pekerja mahir, produktiviti pekerja yang rendah, kapasiti PKS yang terhad untuk beroperasi dalam era globalisasi dan persaingan sengit daripada firma di China dan India (Ting, 2004; Zhen dan Williamson, 2003).

\subsection{Sorotan Literatur}

\subsection{Amalan Perkhidmatan Lean}

Terdapat banyak prinsip pengurusan dan amalan yang baik yang diperkenalkan, namun begitu lean lebih mendapat perhatian. Perhatian diberikan kepada lean kerana lean merupakan falsafah pengurusan yang memberikan fokus untuk menyingkirkan aktiviti yang tidak memberikan nilai tambah dalam sesuatu proses (Womack dan Jones, 2003; Alsmadi dan Khan, 2010; Bortolotti et. al, 2016). Matlamat asas lean adalah untuk menghasilkan produk yang betul pada masa yang tepat dan pada harga yang pelanggan sanggup membayar (Sampson, 2004; Bortolotti,

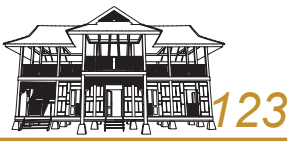


et. al, 2015) dengan menggunakan sumber sedia ada.

Konsep Lean adalah berasal daripada pengeluar Jepun yang telah berkembang ke seluruh dunia selama beberapa dekad lalu melalui Sistem Pengeluaran Toyota (TPS). lanya telah diperkenalkan oleh Taiichi Ohno (1912-1990) dalam usaha untuk bersaing dengan pengeluar kereta Amerika Syarikat (Womack et. al, 1990). Kepentingan Lean sebagai satu amalan terbaik terus menarik perhatian ramai pengkaji dan buku-buku seperti "Mesin Itu Merubah Dunia" (Womack et. al, 1990), "Pemikiran Lean" (Womack dan Jones, 2003) dan "The Way Toyota" (Liker, 2004) diterbitkan sebagai panduan kepada syarikat untuk menjadi lebih cekap dan efisyen (Bortolotti et. al, 2016). Malah penggunaan istilah lean dalam pelbagai bidang seperti pengeluaran lean, pembuatan lean, pemikiran lean, perusahaan lean, teori lean dan falsafah lean (Wicker, 2004) menunjukkan bahawa lean berada pada tahap yang lebih tinggi daripada konsep, strategi, dan budaya.

Oleh itu, amalan perkhidmatan lean merujuk kepada suatu amalan yang wujud dalam syarikat (Damrath, 2012) hasil daripada sistem dan tingkahlaku yang dipraktikkan. Amalan yang dilaksanakan akan menjadi strategi dalam operasi bagi sesebuah syarikat (Karim dan Arif-UzZaman, 2013). Menurut Haksever et. al (2000) tujuan utama sesebuah syarikat melaksanakan amalan perkhidmatan lean adalah untuk mewujudkan nilai kepada pelanggan daripada segi kos, kualiti, harga dan masa penyampaian perkhidmatan. Malah, dalam persekitaran yang semakin kompetitif, kemampuan syarikat perkhidmatan bersaing adalah bergantung kepada nilai perkhidmatan yang diberikan oleh pelanggan, pekerja, pembekal dan pemegang saham (Arfmann et. al, 2014; Andres-Lopez et. al, 2015). Nilai perkhidmatan ini merujuk kepada sesuatu barangan dan perkhidmatan yang mampu memenuhi dan memuaskan serta memberikan faedah kepada pelanggan (Haksever et. al., 2000; Alsmadi et. al, 2012).

\subsection{Prinsip-Prinsip Amalan Perkhidmatan Lean}

Terdapat lima prinsip penting yang perlu diambil kira terutama untuk memastikan nilai tambah kepada pelanggan dapat diberikan dan mengelakkan aktiviti-aktiviti dalam aliran kerja yang mendatangkan pembaziran (Womack dan Jones, 2003; Coleman, 2008; Damrath, 2012; Andres-Lopez et. al, 2015). Lima prinsip tersebut ialah:-

1. Menentukan nilai bagi setiap produk: Diperolehi daripada perspektif pelanggan dan dilihat sebagai sebarang bentuk pengendalian atau proses yang pelanggan bersedia untuk membayar. Nilai perlu memenuhi keperluan pelanggan pada harga dan masa yang tertentu. Pengeluar barang atau perkhidmatan yang baik perlu mencipta nilai melalui penentuan kos sasaran berdasarkan kepada jumlah sumber dan usaha yang dilakukan 
untuk membuat produk secara spesifik dengan menghapuskan semua pembaziran (muda).

2. Mengenalpasti aliran nilai bagi setiap produk (Value Stream): Memahami semua aktiviti yang terlibat dalam sesuatu proses. Tindakan yang spesifik diperlukan untuk membawakan produk atau perkhidmatan yang baik melalui tiga peringkat pengurusan yang kritikal dalam perniagaan iaitu a) penyelesaian masalah b) pengurusan maklumat c) transformasi fizikal

3. Membuat aliran produk secara berterusan: Meminimumkan gangguan semasa proses. Dalam proses aliran apabila aktiviti yang tiada nilai sepanjang proses dihapuskan, langkahlangkah menambah nilai dalam sesuatu proses perlu dibenarkan untuk berlaku. Salah satu halangan utama dalam melaksanakan aliran pemikiran Lean adalah penentangan iaitu menentang cara "biasa" melakukan sesuatu. Dua konsep yang amat penting dalam prinsip ini ialah Kaikaku atau radikal penambahbaikan dan Kaizen atau penambahbaikan yang berterusan.

4. Menggunakan teknik tarik (pull): Mengikut permintaan pelanggan. Prinsip 'tarik' berdasarkan kepada idea bahawa pelanggan meminta produk itu dan setiap langkah dalam sesuatu proses mengikut permintaan pelanggan.

5. Berusaha ke arah kesempurnaan: Matlamat utama adalah pembaziran sifar. Prinsip terakhir akan dicapai secara semula jadi apabila Lean telah dilaksanakan dan pembaziran (muda) dihapuskan.

Prinsip-prinsip ini perlu diberikan perhatian terutamanya bagi mereka yang ingin menjalankan kajian Lean dalam sektor perkhidmatan kerana kekeliruan dan perbahasan telah berlaku yang menyatakan bahawa perkhidmatan tidak boleh dilihat, tidak boleh disentuh serta tidak boleh diukur (George, 2003; Andres-Lopez et. al, 2015) malah, perkhidmatan tidak boleh diperbaiki dengan menggunakan teknik dan alat Lean sahaja (Arfmann et. al, 2014). Walau bagaimanapun, dengan adanya prinsip-prinsip Lean yang juga dikenali sebagai Pemikiran Lean (Womack dan Jones, 2003), sektor perkhidmatan secara meluas boleh mengamalkan inisiatif penambahbaikan yang berharga ini (George, 2003; Adres-Lopez et. al, 2015).

\subsection{Pembaziran Dalam Amalan Perkhidmatan Lean}

Secara amnya, terdapat lapan jenis pembaziran dikenalpasti dalam sektor pengilangan yang

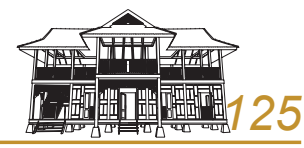


perlu dielak oleh syarikat bagi memastikan amalan Lean mencapai falsafahnya walaupun definisi pembaziran yang dikemukakan oleh pengkaji berbeza. Tujuh jenis pembaziran tersebut ialah menunggu, pengeluaran berlebihan, pengangkutan yang tidak perlu, pemprosesan yang berlebihan/tidak betul (kerumitan), inventori, kecacatan dan kreativiti pekerja yang tidak digunakan (Liker, 2004; Alsmadi et. al., 2012).

Walaubagaiamanapun dalam sistem perkhidmatan pula, Andres-Lopez et. al (2015) telah mengkategorikan lapan pembaziran yang wujud iaitu: -

1. Kelewatan. Masa yang terbuang sama ada secara langsung dalam barisan (contohnya, kertas kerja diletakkan di dalam kotak) atau menunggu untuk maklumat yang akan dihantar (contohnya, seorang individu menunggu beberapa hari sebelum memberi jawapan kepada mesej pesanan suara)

2. Penilaian. Melibatkan aktiviti memeriksa kerja yang telah siap atau separuh siap untuk mengelakkan sebarang ralat. Contohnya mengesahkan penggunaan prosedur perakaunan yang setara atau membuat pembentangan untuk mendapatkan kelulusan pengurusan sebelum meneruskan projek ke fasa seterusnya.

3. Kesilapan. Kesalahan yang berlaku pada peringkat dalaman yang menyebabkan kerja perlu dilakukan semula atau jika didapati oleh pelanggan boleh menyebabkan kehilangan reputasi atau pembelotan pelanggan. Kesilapan juga akan menganggu kelancaran kerja tersebut dan menyebabkan kelewatan dalam aktiviti kerja lain.

4. Pertindihan. Aktiviti yang dilakukan dalam sistem yang sama tetapi boleh dilakukan dengan lebih mudah di bahagian sistem lain. Selain itu, pertindihan wujud ke atas aktiviti yang boleh dilakukan lebih daripada sekali. Sebagai contoh, pertindihan berlaku apabila data yang sama dimasukkan ke dalam sistem borang di dua lokasi yang berbeza.

5. Pergerakan. Melibatkan pengangkutan maklumat fizikal, kakitangan atau peralatan yang tidak diperlukan. Contohnya perjalanan untuk menghadiri mesyuarat untuk mencari punca kesilapan.

6. Ketidakcekapan pemprosesan. Penggunaan sumber yang tidak berkesan dalam melaksanakan sesuatu tugas yang tertentu. Sebagai contoh, membuat laporan tanpa ada format yang setara boleh menyebabkan kakitangan "mencipta semula pusingan kerja" setiap kali laporan dihasilkan 
7. Ketidakcekapan sumber. Cara pengurusan kakitangan, peralatan, bahan-bahan, atau modal yang membazir. Contoh mewujudkan jadual kerja yang tidak bertepatan dengan permintaan pelanggan atau mengadakan mesyuarat yang tidak memberikan nilai tambah kepada pelanggan.

8. Keengganan untuk berubah. Sikap dan sokongan yang kurang daripada pengurusan untuk menggalakkan pekerja terlibat dalam proses penambahbaikan yang berterusan menyebabkan sesuatu cadangan ditolak dengan mudah.

\subsection{Elemen Amalan Perkhidmatan Lean}

Dalam amalan perkhidmatan lean terdapat lima prinsip asas lean yang perlu diberikan perhatian untuk memastikan pelanggan mendapat nilai tambah (Coleman, 2008; AndresLopez et. al, 2015) iaitu:- (a) mengenalpasti penilaian pelanggan - mendapatkan pandangan daripada pelanggan, (b) mengenalpasti aliran penilaian - memahami keseluruhan aktiviti yang terlibat dalam sesuatu proses, (c) pembangunan aliran proses - mengurangkan gangguan semasa proses dijalankan, (d) menggunakan teknik tarik (pull) - pelarasan dengan permintaan pelanggan dan (e) berusaha ke arah kesempurnaan - matlamat pembaziran sifar

Lima prinsip tersebut telah menjadi pegangan pengkaji lepas (Zakaria dan Che Razak, 2011; Malin dan Pär Åhlström, 2011; Shah dan Ward, 2007 dan Arias Aranda, 2002) untuk menjadi asas pengukuran kepada pelaksanaan amalan perkhidmatan lean dalam sektor perkhidmatan PKS. Terdapat sepuluh elemen amalan perkhidmatan lean yang kerap digunakan. Elemenelemen tersebut adalah:-

\subsubsection{Susun Atur perkhidmatan Lean}

Susun atur dalam perkhidmatan lean adalah merujuk kepada sesebuah syarikat perkhidmatan yang mengamalkan susun atur yang memudahkan pergerakan bahan, sumber manusia dan maklumat dalam proses memberikan perkhidmatan yang berkualiti kepada pelanggan. Susun atur yang efektif akan bergantung kepada kos, proses, kualiti kerja dan perhubungan dengan pelanggan. lanya juga mempengaruhi kecekapan organisasi (Andres-Lopez et. al, 2015). 


\subsubsection{Orientasi Tarik (pull)}

Orientasi tarik merupakan suatu falsafah dalam proses pengeluaran. Dalam memberikan perkhidmatan berkualiti, orientasi tarik perlu diberikan perhatian. Menurut Andres-Lopez et. al, (2015), syarikat yang mengamalkan amalan orientasi tarik akan menimbangkan kehendak pelanggan di dalam membangunkan aktiviti perkhidmatan. Permintaan yang tinggi daripada pelanggan terhadap sesuatu perkhidmatan akan menentukan prestasi syarikat.

\subsubsection{Keseragaman Tugas}

Keseragaman tugas merujuk kepada tahap prosedur kerja yang dibangunkan dalam sistem perkhidmatan. Tujuan dibangunkan prosedur kerja yang seragam adalah bagi meminimumkan kecenderungan untuk berubah di dalam proses penyampaian perkhidmatan. Prosedur tersebut dibangunkan mengikut tugas yang spesifik. Proses yang seragam akan meningkatkan kecekapan dan keberkesanan perkhidmatan Lean serta akan mempengaruhi tahap prestasi pekerja dalam melaksanakan tugasan mereka

\subsubsection{Kepelbagaian perkhidmatan yang ditawarkan}

Kepelbagaian perkhidmatan yang ditawarkan merujuk kepada penawaran kepelbagaian perkhidmatan sampingan kepada pelanggan yang mendapatkan perkhidmatan. Contohnya penghantaran perkhidmatan ke rumah. Kepelbagaian ini dapat menentukan segmen pelanggan yang melanggan sesuatu perkhidmatan yang ditawarkan.

\subsubsection{Penggunaan teknologi maklumat}

Penggunaan teknologi maklumat dalam perkhidmatan adalah untuk mengurangkan kos pengeluaran. Kos perkhidmatan dapat dikurangkan dengan menggantikan sumber manusia dengan teknologi maklumat. Selain itu, penggunaan sistem teknologi maklumat dapat membantu syarikat meningkatkan tahap kualiti perkhidmatan yang diberikan kepada pelanggan. Malah menurut Safizadeh et. al, (2003), sistem jaringan komputer berperanan penting dalam membantu syarikat untuk menawarkan perkhidmatan dengan lebih khusus. Syarikat yang dapat menggunakan sepenuhnya teknologi maklumat akan dapat mencipta dan menyampai perkhidmatan dengan lebih cekap dan berkesan kepada pelanggan mereka. Walaupun penggunaan teknologi 
maklumat merupakan komponen yang kritikal dalam sistem perkhidmatan.

\subsubsection{Hubungan aktiviti bahagian hadapan dan belakang pejabat}

Aktiviti bahagian hadapan pejabat adalah merupakan aktiviti yang melibatkan pekerja atau penyedia perkhidmatan dengan pelanggan. Manakala operasi bahagian belakang pejabat merupakan aktiviti yang dilakukan tanpa penglibatan pelanggan dalam proses penyampaian perkhidmatan tersebut. Aktiviti kedua-dua bahagian yang tidak terpisah dan saling berkait akan menjadikan proses penyampaian perkhidmatan lebih cekap dan berkesan kerana pertukaran maklumat berlaku dengan lebih cepat dan mudah. Keadaan ini akan mempengaruhi prestasi syarikat (Gareth dan Lee, 2011) seperti kualiti perkhidmatan, kecekapan perkhidmatan dan kebolehupayaan syarikat menyediakan perkhidmatan dengan berkesan (Gomes et. al, 2007). Bagi memperbaiki keseluruhan prestasi, sistem operasi kedua-dua bahagian ini perlu digabung dan diselaraskan.

\subsubsection{Kepelbagaian fungsi sumber manusia}

Kepelbagaian fungsi sumber manusia merujuk kepada keupayaan sumber manusia untuk melakukan pelbagai tugas. Kepelbagaian keupayaan yang dimiliki, membolehkan pekerja terlibat dengan pelbagai tugasan sama ada secara keseluruhan ataupun sebahagian tugasan sahaja. Selain itu, kebolehan pekerja juga akan meningkat yang akhirnya memudahkan mereka untuk menghadapi perubahan persekitaran. Ini kerana semakin tinggi tahap kepelbagaian fungsi pekerja akan menjadikan mereka lebih cekap dalam melakukan tugas.

\subsubsection{Penglibatan pelanggan}

Penglibatan pelanggan pula merujuk kepada hubungan atau interaksi yang wujud antara pelanggan dengan penyedia perkhidmatan dalam proses menyampaikan perkhidmatan. Hubungan baik yang wujud membolehkan pelanggan saling bertukartukar maklumat dengan penyedia perkhidmatan. Selain itu, pelanggan juga boleh membantu syarikat melakukan tugasan semasa proses penyampaian perkhidmatan dilakukan. Keadaan membantu aktiviti penyampaian menjadi lebih cekap dan berkesan kerana pelanggan sendiri yang melakukan aktiviti yang boleh dikendalikan mereka tanpa penyedia perkhidmatan melakukan aktiviti tersebut. Kesannya, secara tidak langsung menyumbang kepada pengurangan kos operasi pengeluaran syarikat.

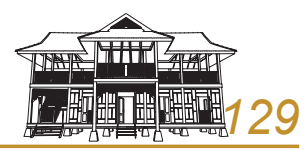




\subsubsection{Pembangunan dan reka bentuk perkhidmatan yang baru}

Pembangunan dan reka bentuk perkhidmatan yang baru merupakan satu proses dalam menyediakan suatu prosedur sistem penyampaian yang baru atau pun membuat pelaburan terhadap sumber yang khusus bagi melancarkan sistem penyampaian perkhidmatan syarikat. Keadaan ini menunjukkan bahawa syarikat berusaha untuk melakukan inovasi terhadap proses yang sedia ada ataupun menyediakan perkhidmatan yang baru kepada pelanggan.

\subsubsection{Pelan Pengenalpastian Pembaziran}

Pelan pengenalpastian pembaziran merujuk kepada proses mengenalpasti aktiviti yang tidak memberikan nilai/kepuasan kepada pelanggan. Proses ini merupakan suatu aktiviti yang penting kerana syarikat boleh memperolehi pelbagai maklumat. Contohnya masa menunggu, pergerakan dan pengangkutan yang tidak berkaitan serta lain-lain pembaziran yang wujud dalam sesuatu proses penyampaian perkhidmatan kepada pelanggan.

\subsection{Permasalahan Amalan Perkhidmatan Lean Dalam Sektor Perkhidmatan Perusahaan Kecil Dan Sederhana}

Amalan perkhidmatan lean telah dikenalpasti dan dipersetujui oleh ramai pengkaji sebagai salah satu mekanisme kelas dunia untuk mengurangkan pembaziran dan meningkatkan nilai tambah kepada pelanggan (Mohd Rose et. al, 2009; Abdul Hamid, 2011; Suárez-barraza et. al, 2012). Pengaplikasian amalan perkhidmatan lean yang tepat akan membantu sesebuah syarikat untuk menghasilkan produk dan perkhidmatan yang berkualiti serta memberikan impak yang positif ke atas prestasi syarikat (Mohd Rose et. al, 2009; Papadopoulos et. al, 2011).

Kejayaan pengaplikasian amalan perkhidmatan lean dalam menyelesaikan masalah syarikat untuk menjadi lebih cekap dapat dilihat dalam kajian yang dijalankan ke atas sektor perkhidmatan kesihatan, terutamanya di hospital awam dan swasta (Kollberg et al., 2007; Radnor dan Walley, 2008; Dickson et. al, 2009; Suárez-barraza et. al, 2012). Selain itu, kajian turut dijalankan dalam bidang lain seperti pendidikan (Comm dan Mathaisel, 2005; Hines dan Lethbridge, 2008; Andres-Lopez et. al, 2015), pelancongan (Julien dan Tjahjono, 2009) serta lain-lain jenis perkhidmatan (Maleyeff, 2006; Piercy dan Rich, 2009) dan didapati berjaya.

Namun begitu, kajian berkaitan amalan perkhidmatan lean dan kejayaan pelaksanaannya 
dalam sektor perkhidmatan perusahaan kecil dan sederhana masih kurang sedangkan sektor perusahaan kecil dan sederhana merupakan penyumbang utama kepada pembangunan ekonomi negara (Womack et. al, 1990; Womack et. al, 1996; Achanga et. al, 2006; Mohd. Rose et. al, 2009; Andres-Lopez et. al, 2015). Selari dengan Pelan Induk SME Malaysia 2012-2020 pada tahun 2012 mendapati PKS telah memberikan sumbangan yang besar kepada bidang perniagaan dengan $99.2 \%$ daripada jumlah pertubuhan perniagaan negara.

Walaubagaimanapun, ketiadaan sumber kewangan yang cukup, tenanga pekerja yang mahir, teknologi yang terkini dan pasaran yang luas (White et. al, 1999; Achanga et. al., 2006; Mohd Rose et. al., 2009; Omar et. al, 2009; Khalique et. al, 2011; SME \& Entrepreneurship Magazine Online, 2012) menyebabkan syarikat PKS berhadapan dengan masalah untuk terus bersaing di pasaran global yang kompetatif tidak kira di mana lokasi mereka.

Masalah-masalah yang wujud ini telah menyebabkan berlakunya pembaziran seperti kelewatan membuat keputusan, penilaian yang lama, kesilapan membuat keputusan, pertindihan kerja, pergerakan yang merugikan, ketidakcekapan sumber, ketidakcekapan pemprosesan dan kreativiti yang tidak digunakan (Alsmadi et. al., 2012) dalam kalangan syarikat PKS. Bukan itu sahaja, pembaziran ini juga telah memberikan kesan ke atas prestasi syarikat di mana prestasi kewangan, kepuasan pelanggan, inovasi dan pertumbuhan pengetahuan serta prestasi dalaman perniagaan menurun yang mengakibatkan kegagalan syarikat untuk kekal bersaing dalam pasaran kompetatif (Alsmadi et. al., 2012).

\subsection{Pelaksanaan Amalan Perkhidmatan Lean Dalam Pelbagai Sektor}

Terdapat banyak kajian literatur yang mengkaji amalan perkhidmatan lean secara empirikal (Arfmann et. al, 2014; Friedrich dan Horst, 2015; Andres-Lopez et. al, 2015; Erwin et. al, 2016; Bortolotti et. al, 2016). Kajian yang dilakukan menunjukkan bahawa amalan perkhidmatan lean meningkatkan prestasi pada peringkat operasi dan juga syarikat secara keseluruhannya. Namun begitu, konsep ini tidak didefinisikan secara konsisten oleh penyelidik yang lepas. Kebanyakan pengkaji menganggap konsep tersebut telah diketahui secara umum dan terdapat sesetengah kajian tidak mendefinisikan konsep ini (Christiansen et. al, 2003). Malah ada juga amalan perkhidmatan lean yang didefinisikan menggunakan contoh (Guisinger dan Ghorashi, 2004; Nahm et. al, 2004). Keadaan ini menunjukkan bahawa adalah sukar untuk menentukan definisi konsep amalan perkhidmatan lean secara tepat.

Selain itu, peranan yang dimainkan oleh amalan perkhidmatan lean adalah tidak jelas disebabkan amalan ini dirujuk dalam keadaan yang berbeza-beza dan pada peringkat yang berlainan. Kebanyakan amalan perkhidmatan lean ini dinilai pada peringkat bawah yang

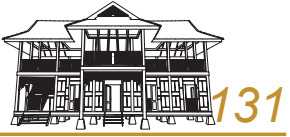


merupakan aktiviti berasingan dan tidak bergantung dengan aktiviti lain untuk mencapai matlamat syarikat yang spesifik. Contohnya penggunaan kawalan proses berstatistik yang menggunakan alatan statistik untuk memerhati prestasi pengeluaran, meramal kerosakan barangan yang menyebabkan barangan ditolak dan mengenal pasti proses semasa di bawah kawalan pengeluaran. Proses ini digunakan untuk mengawal kualiti barangan dan perkhidmatan dalam proses operasi pengeluaran (Erwin et. al, 2016).

Walaubagaimanapun terdapat juga kajian amalan perkhidmatan lean yang dijalankan merujuk kepada peringkat pertengahan dalam operasi pengeluaran barangan dan perkhidmatan. Contohnya amalan hanya pada masa yang dikaji oleh Bortolotti et. al (2016). Kajian ini mempunyai empat elemen iaitu penglibatan pembekal, perpindahan pengetahuan berkaitan lean, komitmen program berkaitan lean, keseragaman program lean. Di samping itu, amalan pengeluaran Lean turut dikaji pada peringkat ini oleh penyelidik (Narasimhan et. al, 2005; Shah dan Ward, 2007) di mana kedua-dua amalan ini dirujuk sebagai amalan sistem atau kumpulan amalan yang diamalkan dalam syarikat.

Bukan itu sahaja, kajian yang dijalankan menggunakan amalan lean seperti amalan hanya pada masa (Fullerton et. al, 2003), amalan pengurusan kualiti menyeluruh (Khairul Anuar, 2002) dan amalan teknologi pembuatan termaju terhadap prestasi (Kotha dan Swamidass, 2000) turut sama dikaji. Selain itu, terdapat penyelidik yang menggunakan amalan lean bersama-sama bagi mengkaji hubungannya dengan prestasi. Antaranya adalah Cua et al., (2001) yang menggabungkan amalan hanya pada masa, pengurusan kualiti menyeluruh dan amalan penyelenggaraan pencegahan menyeluruh terhadap prestasi syarikat. Sementara itu, Challis et. al (2005) mengkaji pengaruh amalan integrasi pembuatan yang meliputi amalan pembuatan termaju, amalan hanya pada masa dan pengurusan kualiti menyeluruh terhadap prestasi pembuatan. Hasil daripada perlaksanaan amalan perkhidmatan lean ini, prestasi operasi dan syarikat yang dikaji telah dapat dipertingkatkan dan ditambahbaik.

Perkembangan dalam bidang kajian ini terus mendapat perhatian apabila terdapat penyelidik yang mengkaji pula faktor-faktor kritikal yang mempengaruhi pelaksanaan amalan perkhidmatan lean. Contohnya, Abdul Hamid (2011) mendapati faktor kepimpinan dan fokus pelanggan menjadi faktor utama mempengaruhi amalan perkhidmatan lean. Sementara itu, terdapat lima sektor perkhidmatan dikenalpasti kerap mengaplikasikan amalan perkhidmatan lean dengan jayanya. Sektor tersebut ialah sektor penjagaan kesihatan (Dahlgaard et. al, 2011; Aherne, 2007; Filingham, 2007; Kollberg et. al, 2007; Lipley, 2008), pendidikan (Atikinson, 2004; Emiliani, 2005; Hines dan Lethbridge, 2008; Pedersen dan Huniche, 2011; Andres-Lopez et. al, 2015), bank dan institusi kewangan (Swank, 2003; Abdi et. al, 2006; Maleyeff, 2006; Piercy dan Rich, 2009), syarikat penerbangan dan bengkel mekanikal (Greenwood et. al, 
2002; Hutchins, 2006; Bortolotti et. al, 2016), serta hotel dan restoran (Suarez-Barraza, 2008; Julien dan Tjahjono, 2009; Erwin et. al, 2016 ). Sektor penjagaan kesihatan merupakan antara sektor yang paling banyak mendapat perhatian untuk dikaji berbanding empat sektor yang lain (pendidikan, perbankan dan institusi kewangan, penerbangan serta hotel dan restoran). Antara sebab sektor ini sering menjadi perhatian adalah kerana peningkatan kos dalam penjagaan kesihatan, kekurangan profesionalisme dan proses birokrasi serta keberkesanan dan kecekapan yang rendah dalam sistem penyampaian mereka (Spear, 2005).

Oleh itu, hipotesis pertama kajian ialah:

Terdapat amalan perkhidmatan lean yang dilaksanakan dalam kalangan sektor perkhidmatan perusahaan kecil dan sederhana (PKS) Malaysia

\subsection{Perkaitan Amalan Perkhidmatan Lean Dengan Prestasi}

Berdasarkan daripada kajian lepas menunjukkan bahawa terdapat hubungan yang kuat antara amalan perkhidmatan lean dengan prestasi syarikat (Christiansen et al., 2003; Verma dan Young, 2000; Shah dan Ward, 2007). Zakaria dan Che Razak (2011) telah mengkaji secara sistematik hubungan antara pelbagai amalan utama Lean dan prestasi syarikat mendapati bahawa syarikat dapat mengekalkan prestasi dengan menggunakan satu atau lebih amalan. Begitu juga dengan kajian Fullerton, Kennedy dan Widener (2014) yang menggabungkan amalan lean dengan kepelbagiaan fungsi teknikal sektor hospitaliti telah menunjukkan hubungan positif dengan peningkatan prestasi kewangan. Kajian oleh Mohd Rizal (2008) juga mendapati bahawa amalan perkhidmatan lean mempunyai hubungan dengan peningkatan prestasi syarikat. Secara umumnya amalan pengurusan terbaik mempunyai hubungan yang positif dengan prestasi syarikat (Dobrzykowski et. al 2016). Oleh itu, dapat disimpulkan penerapan amalan perkhidmatan lean dalam semua fungsi syarikat dapat memberikan kesan positif ke atas prestasi.

Namun begitu, hasil daripada kajian literatur yang dilakukan terdapat juga amalan perkhidmatan lean yang dilaksanakan dalam syarikat menunjukkan hubungan yang tidak signifikan dengan prestasi operasi dan syarikat. Antara kajian tersebut adalah Erwin et.al (2016), yang mengkaji perlaksanaan amalan pengurusan lean terhadap prestasi syarikat sektor perhotelan. Keputusan kajian mereka mendapati bahawa tidak semua amalan pengurusan lean sesuai dilaksanakan dan dapat membantu meningkatkan prestasi syarikat. Contoh pelan pengenalpastian pembaziran (VSM). Sementara itu, Wilson dan Collier (2000) dalam kajian mereka terhadap syarikat yang melaksanakan Malcom Bridge National Quality Award (MBNQA), mendapati bahawa amalan kepimpinan dalam kualiti tidak mempunyai

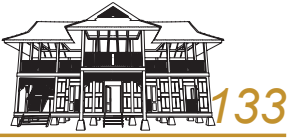


hubungan dengan prestasi kewangan syarikat. Begitu juga dengan kajian oleh Benner dan Veloso (2008) terhadap syarikat yang melaksanakan ISO 9000. Hasil kajian menunjukkan bahawa perlaksanaan ISO 9000 dalam syarikat tidak mempunyai hubungan dengan prestasi kewangan syarikat.

Oleh itu, kajian ini dijalankan untuk melihat hubungan antara amalan perkhidmatan lean dan prestasi syaikat PKS sama ada mempunyai hubungan yang positif dan signifikan atau sebaliknya..

Oleh itu, hipotesis kedua kajian ialah:

Terdapat hubungan yang signifikan antara amalan perkhidmatan lean dengan prestasi

\subsection{Pembentukan Kerangka Kajian}

Rajah dibawah menunjukkan kerangka kajian ini. Kerangka kajian ini adalah gabungan elemen amalan perkhidmatan lean dengan prestasi untuk memberi pengaruh kepada pelaksanaan amalan perkhidmatan lean dalam syarikat. Pembolehubah bebas dalam kajian ini ialah amalan perkhidmatan lean yang berperanan untuk mewujudkan nilai kepada pelanggan daripada segi kos, kualiti, harga, penyampaian yang lancar dan masa yang tepat (Haksever et al., 2000; Zakaria dan Che Razak, 2011) serta memberi kelebihan persaingan kepada syarikat (Arias Aranda, 2003; Andres-Lopez, 2015). Pembolehubah bersandar pula ialah prestasi yang menjadi pengukur tahap keupayaan dalaman yang dimiliki oleh syarikat untuk terus kekal bersaing dalam persekitaran yang kompetitif (Barney, 2001) 


\begin{tabular}{|c|c|}
\hline $\begin{array}{ll} & \text { Amalan Perkhidmatan Lean } \\
& \\
\text { - } & \text { Pelan Pengenalpastian Pembaziran } \\
\text { - } & \text { Kusun Atur } \\
\text { - } & \text { Kepelbagaian Perkhidmatan } \\
\text { - } & \text { Penggunaan teknologi maklumat } \\
\text { - } & \text { Orientasi tolak/tarik } \\
\text { - Penglibatan Pelanggan } \\
\text { - } & \text { Aktiviti bahagian hadapan dan } \\
\text { - } & \text { Kelakang pejabat } \\
\text { - } & \text { Pepelbagaian Fungsi Sumber manusia } \\
& \text { perkhidmatan baru }\end{array}$ & $\begin{array}{c}\text { Prestasi } \\
\text { Organisasi }\end{array}$ \\
\hline
\end{tabular}

Rajah 1: Kerangka kajian 


\subsection{Kesimpulan}

Sorotan kajian lepas mendapati amalan perkhidmatan lean mempunyai hubungan yang signifikan dengan prestasi. Malah amalan perkhidmatan lean berjaya membuktikan prestasi dapat ditingkatkan melalui pelaksanaannya dalam organisasi atau syarikat yang terlibat (Arias Aranda, 2002; Mohd Rizal, 2008; Zakaria dan Che Razak, 2011). Namun begitu, kajian empirikal tentang hubungan amalan perkhidmatan lean dengan prestasi khususnya dalam sektor perkhidmatan PKS masih kurang. Oleh itu, Penulisan ini mengemukakan kerangka konseptual yang boleh dijadikan rujukan bagi kajian akan datang berkaiatan perkhidmatan LEAN. 


\section{Rujukan}

Abdul Hamid, R. (2011). Factors Influencing The Success Of Lean Services Implementation : Conceptual Framework. 2nd International Conference On Business And Economic Research (2nd Icber 2011) Proceeding (Pp. 1496-1509).

Abdi, F., Khalili Shavarini, S.,\& Seyed Hoseini, S.M. (2006). GLean Lean: How to use Lean approach in service industries? Journal of Services Research, 6, 191-206.

Achanga, P., Shehab, E., Roy, R., \& Nelder, G. (2006). Critical success factors for Lean implementation within SMEs. Journal of Manufacturing Technology Management, 17(4), 460-471. doi:10.1108/17410380610662889

Aherne, J. (2007). Think Lean. Nursing Management, 13(10), 13-15

Andres-Lopez, E., Gonzalez-Requena, I., \& Sanz-Lobera, A. (2015). Lean Service: Reassessment of Lean Manufacturing for Service Activities. The Manufacturing Engineering Society International Conference, MESIC 2015. Procedia Engineering 132 (2015). 23-30.

Arfmann, D., Federico, \& Topolansky Barbe, G., (2014). The Value of Lean Service Sector: A Critique of Theory \& Practice. International Journal of Business and Social Science 5(2).

Alsmadi, M., Almani, A., \& Jerisat, R. (2012). Total Quality Management dan Business Excellence A comparative analysis of Lean practices and performance in the UK manufacturing and service sector firms. Total Quality Management, 23(June 2013), 37-41.

Andres-Lopez, E., Gonzalez-Requena, I., \& Sanz-Lobera, A. (2015). Lean Service: Reassessment of Lean Manufacturing for Service Activities. The Manufacturing Engineering Society International Conference, MESIC 2015. Procedia Engineering 132 (2015). 23-30.

Arias Aranda, D. (2002). Relationship between operations strategy and size in engineering consulting firms. International Journal of Service Industry Management, 13(3), 263-285.

Arias Aranda, D. (2003). Service operation strategy, flexibility and performance in engineering consulting firms. International Journal of Operations and Production Management, 23(11), 1401-1421.

Atkinson, P., (2004). Creating and implementing Lean strat- egies. Management Services, 48 (2), 18-33

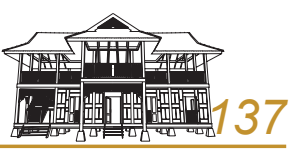


Barney, J.B. (2001b). Resource based theories of competitive advantage: a ten year retrospective on the resource based view. Journal of Management, 27, 643-650.

Bortolotti, T., Danese, P., Flynn, B. B. \& Romano, P. (2015). Leveraging fitness and lean bundles to build the cumulative performance sand cone model. International Journal Prodcution Economics 162: 227-241

Bortolotti, T., Romano, P., Martinez-Jurado, J. P. \& Moyano-Fuentes, J. (2016). Towards a theory for lean implementation in supply networks. International Journal Production Economics. 175: 182-196.

Coleman, S. (2008). Six Sigma: An opportunity for statistics and for statisticians.

Significance, 5, 94-96.

Comm, C. L., \& Mathaisel, D. F. X. (2005). An exploratory study of best Lean sustainability practices in higher education. Quality Assurance in Education, 13, 227-240.

Challis, D.J., Samson, D., \& Lawson, B. (2005). Impact of technological, organization and human resource investment on employee and manufacturing performance: Australia and New Zealand evidence. International Journal of Production Research, 43(11), 81-107.

Christiansen, T., Berry, W. L., Bruun, P., \& Ward, P. (2003). A mapping of competitive priorities, manufacturing practices, and operational performance in groups of Danish manufacturing companies. International Journal of Operations and Production Management, 23(10), 1163-1183.

Cua, K.O., McKone, K.E., \& Schoreder, R.G. (2001). Relationship between implementation of TQM, JIT and TPM and manufacturing performance. Journal of Operations Management, 19, 675-694.

Dahlgaard, J.J., \& Dahlgaard-Park, S.M. (2006). Lean production, six sigma quality, TQM and company culture. TQM Magazine, 18(3), 263-281

Damrath, F. (2012). Increasing competitiveness of service companies: developing conceptual models for implementing Lean Management in service companies.

Dickson, E. W., Singh, S., Cheung, D. S., Wyatt, C. C., \& Nugent, A. S. (2009). Application of Lean manufacturing techniques in the emergency department. The Journal of Emergency Medicine, 37, 177-182.

Dobrzykowski, D. D., Kathleen, L. M. \& Mark, V. A. (2016). Examining pathways to safety and financial performance in hospitals: A study of lean in professional service operations. Journal of Operations Management. 1-13 
Emiliani, M.L. (2005). Using Kaizen to improve the graduate business school degree program. Quality Assurance in Education, 13(1), 37-52.

Erwin, R., Andreas, D., Philipp, H. \& Dominik, T. M. (2016). Lean Hospitality-Application of Lean Management methods in the hotel sector. $48^{\text {th }}$ CIRP Coference on Manufacturing Systems - CIRP CMS 2015. Procedia CIRP 41: 614-619

Fullerton, R.R., McWatters, C.S., \& Fawson, C. (2003). An examination of the relationship between JIT and financial performance. Journal of Operations Management, 21(4), 383-404.

Fullerton, R.R., Kennedy, F.A. \& Widener, S.K. (2014). Lean Manufacturing and firm performance: the incremental contribution of lean management accounting practices. Journal Operations Management. 32: 414-428.

Friedrich, M. \& Horst, M. (2015). Service Value Stream Mapping in Industrial Product-Service System Performance Management. $7^{\text {th }}$ Industrial Product-Service Systems Conference-PSS, industry transformation for sustainabilty and business. Procedia CIRP 30: 457-461.

Gareth, D.F. \& Lee, J. (2011). Lean Construction Submittal Process-A case study. Quality Engineering. 23:84-93

George, M. L. (2003). Lean Six Sigma for service: How to use Lean speed and Six Sigma quality to improve services and transactions. McGraw-Hill: USA.

Gomes, C.F., Yasin, M.M., \& Lisboa, J.V. (2007). The effectiveness of hospitality service operations: measurement and implementation concerns. International Journal of Contemporary Hospitality Management, 19(7), 560-573.

Guisinger, A., \& Ghorashi, B. (2004). Agile manufacturing practices in the speciality chemical industry. International Journal of Operations \& Production Management, 24(6), 364-350.

Greenwood, T., Bradford, M., \& Green, B. (2002). Becoming a Lean enterprise: A tale of two firms. Strategic Finance, 84(5), 32-39.

Haksever, C., Render, B., Russel, R.S., \& Murdick, R.G., (2000). Service Management and Operation, 2nd Ed, Prentice Hall International UK. London.

Hines, P., \& Lethbridge, S. (2008). New development: Creating a Lean university. Public Money dan Management, February. 
Hutchins, K. (2006). United Airlines says goodbye to "the Big B". Ground Support Magazine, 14(3), 14-17 Julien, D. M., \& Tjahjono, B. (2009). Lean thinking implementation at a safari park. Business Process Management Journal, 15(3), 321-335. doi:10.1108/14637150910960585

Karim, A. \& Arif-Uz-Zaman, K. (2013). A methodology for effective implementation of lean strategies and its performance evaluation in manufacturing organizations. Business Process Management, 19 (1), 169196.

Khalique, M., Hassan Md. Isa, A., Abdul Nassir Shaari, J., \& Ageel, A. (2011). Challenges Faced By The Small Dan Medium Enterprises ( Smes ) In Malaysia: An Intellectual Capital Perspective. International Journal of Current Research, 3(2010), 398-401.

Khairul Anuar Mohd Ali. (2002). Hubungan amalan pengurusan kualiti cemerlang dengan kepuasan pelanggan dalaman dan prestasi organisasi Pihak Berkuasa Tempatan di Semenanjung Malaysia. (Ph.D Tesis tidak diterbitkan). Universiti Utara Malaysia, Malaysia.

Kollberg, B., Dahlgaard, J. J., \& Brehmer, P.-O. (2007). Measuring Lean initiatives in health care services: issues and findings. International Journal of Productivity and Performance Management, 56(1), 7-24. doi:10.1108/17410400710717064

Kotha, S., \& Swamidass, P.M. (2000). Strategy, advance manufacturing technology and performance: empirical evidence from U.S manufacturing firms. Journal of Operations Management, 18(3), 257-277.

Liker, J. K., (2004). 'The Toyota Way 14 Management Principles from the World Greatest Manufacturer', Mc Graw Hill, ISBN 0-07139231-9.

Lipley, N. (2008). Lean times ahead. Nursing Management, 15(1), 1-3.

Maleyeff, J. (2006). Exploration of internal service system using Lean principles. Management Decision, 44, 674- 689.

Mohd Rizal Razalli. (2008). The consequences of service operation practice and service responsiveness on hotel performance. Examining hotel in Malaysia. Unpublished Ph.D thesis Universiti Sains Malaysia.

Mohd Rose, A. N., Mohd Deros, B., \& Abdul Rahman, M. N. (2009). A Review on Lean Manufacturing practices in Small and Medium Entreprise. Seminar 3 - AMReG 09, 29 Julai 2009, Kajang,Selangor, Malaysia. AMReG 09.

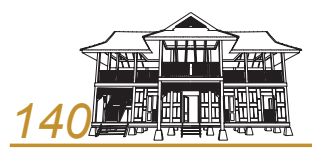


Nahm, A. Y., Vonderembse, M. A., \& Koufteros, X. A. (2004). The impact of organizational culture on timebased manufacturing and performance. Decision Science, 35(4), 579-607.

Narasimhan, R., Swink, M., \& Kim, S. W. (2005). An exploratory study of manufacturing practice and performance interrelationship. Implications for capabilities progression. International Journal of Operations and Production Management, 25(10), 1013-1033.

Omar, S. S., Arokiasamy, L., \& Ismail, M. (2009). The Background and Challenges Faced by the Small Medium Enterprises. A Human Resource Development Perspective. International Journal of Business and Management, 4(10), 95-102.

Papadopoulos, T., Radnor, Z., \& Merali, Y. (2011). The role of actor associations in understanding the implementation of Lean thinking in healthcare. International Journal of Operations dan Production Management, 31(2), 167-191. doi:10.1108/01443571111104755

Pedersen, E.R.G. \& Huniche, M. (2011). "Determinants of Lean success and failure in the Danish public sector: a negotiated order perspective", International Journal of Public Sector Management, Vol. 24 No. 5, pp. 403-20.

Piercy, N., \& Rich, N. (2009). Lean transformation in the pure service environment: the case of the call service centre. International Journal of Operations dan Production Management, 29(1), 54-76. doi:10.1108/01443570910925361

Radnor, Z. \& Walley, P. (2008). Learning to walk before we try to run: Adapting Lean for the public sector. Public Money dan Management February: 13-20.

Safizadeh, M.H. Ritzman, L., \& Mallick, D. (2003). Alternative paradigms in manufacturing strategy. Production and Operations Management, 9(2), 111-127.

Sampson, M. (2004). Nonprofit, payload process improvement through Lean management. Dissertation: University of Colorado.

SME \& Entrepreneurship Magazine Online (2012). Main Challenges Facing SMEs, 'SME 100, Are you fast enough?', Malaysi's Fast Moving Companies. pg. 91-96. http://smemagazine.asia/smeceoforum/ SME\%20100.pdf

Spear, S.J. (2005). Fixing health care from inside, today. Harvard Business Review, 83(8), 78-91.

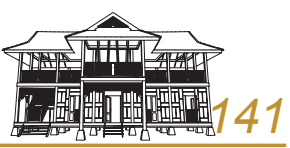


Suárez-barraza, M. F., Smith, T., \& Dahlgaard-park, S. M. (2012). Total Quality Management dan Business Excellence Lean Service : A literature analysis and classification. Total Quality Management, Vol.23, No(June 2013), 37-41. doi:http://dx.doi.org/10.1080/14783363.2011.637777

Swank, C.K. (2003). The Lean service machine. Harvard Business Review, 81(10), 123-130.

Taylor, P., Bortolotti, T., \& Romano, P. (2012). Production Planning dan Control : The Management of Operations "Lean first , then automate ": a framework for process improvement in pure service companies . A case study. Production Planning dan Control (Vol. 23, No.7, pp. 37-41) doi:http://dx.doi.org/10.1080/0 9537287.2011.640040

Ting, O. K. (2004). 'SMEs in Malaysia: Pivot Points for Change' (cited 25 December 2009) Available from: http://www/mca.org.my.

White, R.E., Pearson, J.N. \& Wilson, J.R. (1999). JIT Manufacturing: A survey of implementations in small and large U.S. manufacturers. Management Science.

Wicker, A. L. (2004). The language of Lean: systems action research concerning Design engineers'use of Lean metaphors. Dissertation: University of Phoenix

Womack, J.P., Jones, D.T., \& Roos, D. (1990). The machine that changed the world. New York: Harper Perennial

Womack, J.P., \& Jones, D.T. (1996). Lean thinking: Banish waste and create wealth in your corporation. New York: Free Press.

Womack, J. \& Jones, D. T. (2003). Lean Thinking, Simon dan Schuster, London.

Zakaria, M. N. \& Che Razak, R. (2011). Amalan Sistem Penyampaian Perkhidmatan dan Prestasi Pihak Berkuasa Tempatan. International Conference on Management. (ICM, 2011) Proceeding.

Zakaria, M. N., Al-Mamun, A., Che Nawi, N. \& Md. Nasir, N. (2015). Service Operations Practice and Performance of Local Authorities in Malaysia. Proceedings of the Asia Pasific Conference on Business and Social Sciences. ISBN 978-0-9925622-2-9.

Zhen, M. \& Williamson, P.J. (2003). Hidden dragons. Business Harvard Review 10:92-99

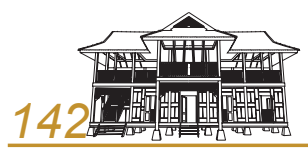

TENIAE 
